\title{
Simple Methodology for the Quantitative Analysis of Fatty Acids in Human Red Blood Cells
}

\author{
Raquel O. Rodrigues ${ }^{1,2} \cdot$ Helena Costa ${ }^{2}$ Rui Lima ${ }^{2,3,4} \cdot$ Joana S. Amaral $^{2,5}$
}

Received: 13 April 2015 / Revised: 7 July 2015 / Accepted: 13 July 2015 / Published online: 28 July 2015

(C) Springer-Verlag Berlin Heidelberg 2015

\begin{abstract}
In the last years, there has been an increasing interest in evaluating possible relations between fatty acid (FA) patterns and the risk for chronic diseases. Due to the long life span (120 days) of red blood cells (RBCs), their FA profile reflects a longer term dietary intake and was recently suggested to be used as an appropriate biomarker to investigate correlations between FA metabolism and diseases. Therefore, the aim of this work was to develop and validate a simple and fast methodology for the quantification of a broad range of FAs in RBCs using gas chromatography with flame ionization detector, as a more common and affordable equipment suitable for biomedical and nutritional studies including a large number of samples. For this purpose, different sample preparation protocols were tested and compared, including a classic two-step method (Folch method) with modifications and different one-step
\end{abstract}

R. O. Rodrigues and H. Costa have contributed equally to this work.

Joana S. Amaral

jamaral@ipb.pt

1 LCM-Laboratory of Catalysis and Materials-Associate Laboratory LSRE/LCM, Faculdade de Engenharia da Universidade do Porto (FEUP), R. Dr. Roberto Frias, 4200-465 Porto, Portugal

2 Polytechnic Institute of Bragança, ESTiG/IPB, C. Sta. Apolónia, 5301-857 Bragança, Portugal

3 CEFT, Faculdade de Engenharia da Universidade do Porto (FEUP), R. Dr. Roberto Frias, 4200-465 Porto, Portugal

4 Mechanical Engineering Department, University of Minho, Campus de Azurém, 4800-058 Guimarães, Portugal

5 REQUIMTE, Departamento de Ciências Químicas, Faculdade de Farmácia Universidade do Porto, Rua de Jorge Viterbo Ferreira no 228, 4050-313 Porto, Portugal methods, in which lipid extraction and derivatization were performed simultaneously. For the one-step methods, different methylation periods and the inclusion of a saponification reaction were evaluated. Differences in absolute FA concentrations were observed among the tested methods, in particular for some metabolically relevant FAs such as trans elaidic acid and eicosapentaenoic acid. The one-step method with saponification and $60 \mathrm{~min}$ of methylation time was selected since it allowed the identification of a higher number of FAs, and was further submitted to in-house validation. The proposed methodology provides a simple, fast and accurate tool to quantitatively analyse FAs in human RBCs, useful for clinical and nutritional studies.

Keywords GC-FID $\cdot$ Fatty acids $\cdot$ Red blood cells $\cdot$ Onestep method

\section{Introduction}

Fatty acids (FAs) are key molecules in living organisms, being involved in several metabolic functions, such as energy storage, membrane structure, signal transduction cascades and protein acylation [1]. In the past three decades, several studies have shown a correlation between the modern western diet, which is considered to be unbalanced due to its richness in n-6 polyunsaturated fatty acids (PUFA) and low levels of n-3 PUFA, and the epidemiology of some chronic diseases, namely cardiovascular diseases [2-5], diabetes [6-8] cell carcinoma [9], Alzheimer's disease [10] and depression [11], among others. Although some epidemiological studies performed so far to evaluate the relation between diet and diseases have relied on data from food frequency questionnaires to assess dietary intake, this approach has several limitations [12]. Therefore, there 
has been an increased interest in using tissue and blood FA composition as biological markers for fat intake [12]. Among the blood constituents, plasma is the most frequently used sample in human studies, possibly due to the general idea that FA composition of specific tissues follows the same pattern than plasma [13], while red blood cells (RBCs) are frequently discarded [14]. However, plasma lipids are known to be related with recent dietary intake and the endogenous processing of lipids, thus being sensitive to dietary fluctuations and representing only a shortterm FA status of the individual [13]. By the contrary, due to the long life span of RBCs, approximately 120 days [15], their FA profile can be used as a biomarker that reflects a longer term dietary macronutrient intake. Additionally, several authors have suggested that FA composition of RBCs can also be used as an appropriate biomarker to investigate patterns of FA metabolism and diseases [3-11].

The analysis of FAs in RBCs typically involves a twostep procedure with the first step consisting in the extraction of the total lipids, followed by a second step that consists in their methylation, with or without previous saponification [16]. Generally, the methodologies used to extract total lipids from RBCs are based either in classic lipid extraction procedures, namely the Folch method [13, $14,17-21]$ and the modified Bligh and Dyer method [2224], or in specific modifications of those methods that generally involve the change of solvent ratios and/or volumes or the use of less toxic solvents. However, this type of procedure is generally considered to be cumbersome and time consuming and can be responsible for sample loss [25, 26]. Nevertheless, in several nutritional or biomedical studies that included the analysis of RBCs FA profile, classic twostep extraction methodologies are still being used [3-7, 17, $18,21,34]$. The main advantages of one-step compared to the two-step procedures are mainly its fastness, precision and simplicity [31]. Therefore, in the last years, several works are available in the literature focusing on the development of one-step procedures (extraction and methylation performed on the same vial) concerning the analysis of FAs in different biological matrices, in particular human plasma [25, 27-31], whole blood [32] and more recently animal or human RBCs [16, 25, 33].

As referred, the analysis of FAME composition in RBCs is increasingly being reported as a parameter included in nutritional assessment or clinical studies. However, to the best of our knowledge, most works do not report absolute quantification of FAMEs, only giving results as relative percentages, and several of them do not even refer the use of internal standard [3-5, 18, 21]. Moreover, and possibly because GC-FID analysis is such a well-established technique for the analysis of FAMEs in different matrices, several clinical and nutritional studies also do not refer the use of calibration with FAME standards (standards only being used for peak identification) and most do not give information about validation data or refer the use of a validated method for RBCs analysis.

For the presented reasons, the proposal of a simple and fast one-step methodology specifically validated for the quantitative determination of FA composition in RBCs is still needed. Therefore, the aims of this study were (1) the optimization of a fast one-step methodology for the quantification of a broad range of FAs in human RBCs using GCFID, since it is a more common and affordable equipment compared to GC with mass spectrometry detection, being suitable for surveys including a large number of samples; and (2) the validation of the proposed method. For that purpose, different sample preparation protocols were tested and compared, including a classic two-step method (Folch method) with slight modifications and different one-step methods, in which the inclusion of a saponification reaction and the use of different methylation time were evaluated. The methodology considered as giving the best results was then submitted to in-house validation.

\section{Materials and Methods}

\section{Reagents and Standards}

Butylated hydroxytoluene (BHT), magnesium sulphate, potassium hydroxide and dichloromethane (DCM) were purchased from Sigma-Aldrich Chemical Co. (St. Louis, USA), physiological salt solution (PSS) containing $0.9 \%$ $\mathrm{NaCl}$ was purchased from $\mathrm{B}$. Braun Medical (Melsungen, Germany), sodium chloride and analytical-grade methanol were purchased from AnalaR Normapur (Radnor, USA), boron trifluoride methanolic solution $\left(20 \% \mathrm{BF}_{3}-\mathrm{MeOH}\right)$ was purchased from Merck Schuchardt (Hohenbrunn, Germany) and HPLC grade $n$-heptane was obtained from Chromanorm Co. (Radnor, USA). A mixture of different FAME standards (37 Component FAME Mix, reference CRM47885) was purchased from Supelco (St. Louis, USA) and the internal standard (IS) methyl nonadecanoate (C19:0 FAME) was purchased from Sigma (St. Louis, USA).

\section{RBCs Sample Preparation}

Venous blood samples were collected into $10 \mathrm{~mL}$ BDVacutainers ${ }^{\circledR}$ (Franklin Lakes, USA) tubes containing ethylenediaminetetraacetic acid (EDTA). Immediately after collection, the whole blood samples were centrifuged at $2500 \mathrm{rpm}$ for $10 \mathrm{~min}$ at $4{ }^{\circ} \mathrm{C}$. After removing the buffy coat and plasma of each sample, the packed RBCs were resuspended and washed twice in PSS. Finally, BHT was added as antioxidant to the RBCs samples in a final concentration of $90 \mu \mathrm{M}$ and the samples were stored at $-20{ }^{\circ} \mathrm{C}$. All FAs 
analyses were performed within a maximum of 4 weeks after storage. All study subjects gave informed consent for participation in the study.

\section{Methodologies for FAMEs Sample Preparation}

Three different lipid extraction-derivatization methods were tested in samples of human RBCs, namely a twostep procedure based on a classic method for lipid extraction (Folch method), a one-step procedure designated as Rapid Method (RM), and a one-step procedure with a quick saponification step, designated as Rapid Method with Saponification (RMS). Furthermore, for both the proposed rapid methods, the optimal transesterification time was evaluated. For this purpose, both RM and RMS procedures were tested using a transesterification reaction at $90{ }^{\circ} \mathrm{C}$ during 30 or $60 \mathrm{~min}$. The procedures, totalizing five different protocols, were executed as described below.

\section{Lipid Extraction using the Folch Procedure with Modifications: Classic Method (CM)}

Total lipids were extracted from human RBCs using the Folch method [20] with slight modifications. In brief, 150 $\mu \mathrm{L}$ of RBCs sample was lysed and washed with deionized water to obtain cell. Then, $1.5 \mathrm{~mL}$ of DCM-methanol solution $(2: 1, \mathrm{v} / \mathrm{v})$ containing $25 \mu \mathrm{g}$ of IS (C19:0 FAME) and $100 \mu \mathrm{M}$ of BHT methanolic solution was added to RBCs cell. Tubes were capped and vigorously vortexed for $30 \mathrm{~s}$, followed by centrifugation for $2 \mathrm{~min}$ at $14,000 \mathrm{rpm}$. The lower layer containing the DCM phase was transferred to a small glass vial and evaporated under nitrogen gas at room temperature. The total lipid components were then transmethylated using $2 \mathrm{~mL}$ of $\mathrm{BF}_{3}$ methanolic solution at $90{ }^{\circ} \mathrm{C}$ during $30 \mathrm{~min}$. After cooling the samples, NaCl-saturated aqueous solution was added to promote the salting out of FAMEs, as well as $1 \mathrm{~mL}$ of $n$-heptane for FAMEs extraction. The supernatant containing the FAMEs was then transferred to a clean glass vial, evaporated to dryness under nitrogen gas and redissolved in $100 \mu \mathrm{L}$ of $n$-heptane for GC-FID analysis.

\section{Direct Extraction and Transmethylation: Rapid Method (RM)}

Total RBCs lipids were extracted and FAs were methylated using the one-step procedure according to Bicalho and coworkers [32] with modifications. In brief, in a $7 \mathrm{~mL}$ glass vial, $2 \mathrm{~mL}$ of $\mathrm{BF}_{3}$ methanolic solution was directly added to $150 \mu \mathrm{L}$ of RBCs samples containing $25 \mu \mathrm{g}$ of IS and $100 \mu \mathrm{M}$ of BHT methanolic solution. Vials were capped and vigorously vortexed for $30 \mathrm{~s}$, followed by a nitrogen flushing to prevent FAMEs degradation. Transmethylation was performed at $90{ }^{\circ} \mathrm{C}$ and two reaction times were evaluated (30 and $60 \mathrm{~min}$ ). After cooling the samples, $1 \mathrm{~mL}$ of $n$-heptane was added and FAMEs were extracted twice by vortex mixing (30 s). Supernatant was then transferred to a clean glass vial and evaporated under nitrogen gas. Samples were resuspended in $100 \mu \mathrm{L}$ of $n$-heptane and the GCFID analysis was performed.

\section{Direct Extraction and Transmethylation: Rapid Method with Saponification (RMS)}

To assess the effect of saponification, the above-described method was slightly modified and the following protocol was used. In a $7 \mathrm{~mL}$ glass vial, $150 \mu \mathrm{L}$ of RBCs sample containing $25 \mu \mathrm{g}$ of IS and $100 \mu \mathrm{M}$ of BHT methanolic solution was added and mixed with $500 \mu \mathrm{L}$ of methanolic $\mathrm{KOH}$ solution $(0.2 \mathrm{M})$. Vials were capped and vigorously vortexed for $30 \mathrm{~s}$, followed by a nitrogen flushing. Saponification was performed at $90{ }^{\circ} \mathrm{C}$ during $10 \mathrm{~min}$. After cooling the samples, $2 \mathrm{~mL}$ of $\mathrm{BF}_{3}$ methanolic solution was added and the vials were vortexed for $30 \mathrm{~s}$, followed by nitrogen flushing. Transmethylation was performed at $90{ }^{\circ} \mathrm{C}$ and two reaction times were also evaluated (30 and $60 \mathrm{~min}$ ). After cooling the samples, $1 \mathrm{~mL}$ of $n$-heptane was added and FAMEs were extracted twice by vortex mixing (30 s). The supernatant was transferred to a clean glass vial and evaporated under nitrogen gas. Finally, samples were resuspended in $100 \mu \mathrm{L}$ of $n$-heptane and analysed by GC-FID.

\section{GC-FID Analysis}

Individual FAMEs were identified using a Bruker ${ }^{\circledR}$ SCION 436-GC gas chromatograph equipped with a flame ionization detector (GC-FID), a split-splitless injector and a Bruker CP-8410 autosampler. FAMEs were separated using a fused carbon-silica column, coated with cyanopropyl phase (CP-Sil 88, $50 \mathrm{~m} \times 0.25 \mathrm{~mm}$ i.d and $0.20 \mu \mathrm{m}$ film thickness, Agilent $\mathrm{J} \& \mathrm{~W})$. The injector temperature was maintained at $260{ }^{\circ} \mathrm{C}$, the split ratio was $1: 25$ and the sample injected volume was $1 \mu \mathrm{L}$. The carrier gas was helium with a total flow rate of $12.4 \mathrm{~mL} \mathrm{~min}^{-1}$ corresponding to a column flow of $1.0 \mathrm{~mL} \mathrm{~min}{ }^{-1}$. The oven temperature was set at $160{ }^{\circ} \mathrm{C}$ and held for $3 \mathrm{~min}$, increased at $3{ }^{\circ} \mathrm{C} \mathrm{min}{ }^{-1}$ to $229{ }^{\circ} \mathrm{C}$ and maintained for $2 \mathrm{~min}$, giving a total run time of $28 \mathrm{~min}$. The FID temperature was set at $270{ }^{\circ} \mathrm{C}$ with the following gas flow: hydrogen $=35 \mathrm{~mL} \mathrm{~min}^{-1}$, instrument air $=350 \mathrm{~mL} \mathrm{~min}^{-1}$ and nitrogen make-up gas $=30 \mathrm{~mL} \mathrm{~min}^{-1}$. A sampling frequency of $50 \mathrm{~Hz}$ was used. Data acquisition and processing were performed using the CompassCDS 3.0 (Bruker, Germany) software for GC systems. 


\section{Identification and Quantification of FAMES}

Sample FAME peaks were identified using the Certified Reference Material of 37 component FAME mix from Supelco. Quantification of individual FA was based on the obtained peak area from triplicate sample extractions, each being injected three times in the GC-FID. The FAME concentrations (ng $\mu \mathrm{L}^{-1}$ ) were calculated using an eight-level calibration curve individually constructed for each FAME, and normalized based on the peak area of the IS. The first level of each FAME was set as the initial concentration of the compound in the Certified Reference Material (37 Component FAME Mix, reference CRM-47885) and the following levels obtained by serial dilution (Table 2). In addition, some peaks that were not present in the Certified Reference Material, namely the FAMEs C18:1n7, C18:1n6, C22:4n6, C22:5n6, $\mathrm{C} 24: 2 \mathrm{n} 6, \mathrm{C} 22: 5 \mathrm{n} 3$, were identified based on data from literature [32] and quantified using the IS (C19:0 FAME) calibration curve. Finally, the individual amount obtained for each FAME was converted to FA concentration using conversion factors FAME > FA proposed by Sheppard (1992) [36].

\section{Method Validation}

The selected procedure for FA extraction from human RBCs and derivatization to FAMEs for GC-FID analysis was subjected to validation according to the general guidelines for the validation of chromatographic methods [37]. With this regard, FID response linearity and the limits of detection (LOD) and quantification (LOQ) were calculated, as well as the precision (repeatability and intermediate precision) and recovery of the analytical procedure. The linearity of the FID response was determined from the triplicate analyses of Certified Reference Material containing 37 component FAME mix and seven serial dilutions prepared from the stock solution. Eight-point calibration curves were obtained for each FAME by plotting peak area versus concentration and linear regressions were calculated. The LOD and LOQ were calculated from the standard deviation of the blank analysis and the slope of the calibration curves of each individual FAME, as described by the International Conference on Harmonisation Guideline [38]. Repeatability and intermediate precision of the selected method were calculated on the basis of the corresponding coefficient of variation (CV \%). Repeatability (intraday precision) was assessed from one sample of RBCs analysed sixfold within 1 day and the interday precision was determined by analysing the same sample of RBCs in duplicates during 5 days. Recovery was assessed by spiking RBCs samples with 15 and $25 \mu \mathrm{L}$ of the pure 37 FAMES Certified Reference Material, each in duplicate. Recoveries were separately calculated and results presented as the mean value of the spiking assays.

\section{Results and Discussion}

\section{Comparison of Sample Preparation Methodologies}

As referred, several methodologies previously reported for the analysis of FAs in biological matrices are frequently based in two-step protocols. Similar to what already has been described for other matrices such as plasma [19] and whole blood [32], this work aimed at proposing a faster sample preparation methodology based on a one-step approach to be used specifically on RBCs analysis. For such purpose, different one-step protocols [designated as rapid methods (RM)] were assayed and compared with a classic two-step method (Folch method with modifications). For the rapid methods, different parameters were evaluated, namely the methylation period and the inclusion of saponification reaction. Bicalho and co-workers [32] evaluated the derivatization yield at several time points (ranging from 5 to $60 \mathrm{~min}$ ) and obtained maximum yields when methylation was performed at $90{ }^{\circ} \mathrm{C}$ during $30 \mathrm{~min}$. Since a different acid catalyst for FAMEs production was used by Bicalho and co-workers [32], in this work methylation times of 30 and $60 \mathrm{~min}$ were tested. Additionally, considering that the inclusion of saponification reaction is frequently mentioned in FA analysis of other matrices, such as vegetable oils [39, 40] and meat [41], the inclusion of saponification was also assayed, resulting in a total of four one-step protocols tested. For all methodologies, based on literature data, BHT was used as antioxidant to prevent samples FA degradation, C19:0 was used as IS and $\mathrm{BF}_{3}$ as a catalyst for FA methylation. BHT, a synthetic antioxidant frequently included in routine analyses [33-35], was used since it promotes PUFA stability during long-term storage of RBCs (4-17 weeks) at $-20{ }^{\circ} \mathrm{C}$ [42]. C19:0 was selected as IS because this odd-chain FA has a microbial origin, therefore inexistent or being present only at trace levels in animal tissues [43]. Although different odd-chain FAs, namely C13:0 and C15:0 have been used in other works, the selected IS has a medium size chain, thus being more adequate as it is similar to the majority of FAs expected to be found in RBCs. $\mathrm{BF}_{3}$ was selected as catalyst for FA methylation due to its availability as commercial reagent and its generalized use. In fact, after the work published by Morrison and Smith in 1964 [44] showing that this reagent could be used to transesterify most of all lipid classes, $\mathrm{BF}_{3}$ has been intensively applied for the analysis of FA in different matrices $[5,13,17,22,25,27,32,34]$. Moreover, the use of $\mathrm{BF}_{3}$ is recommended for FAMEs preparation by the International Union of Pure and Applied Chemistry (IUPAC) [45] and the International Association of Official Analytical Communities (AOAC) [46]. 
Table 1 Comparison of fatty acid (FA) composition ( $\mathrm{ng} \mu \mathrm{L}^{-1}$ ) using different transesterification methods and analysed by GC-FID

\begin{tabular}{|c|c|c|c|c|c|c|c|c|c|c|}
\hline \multirow[t]{2}{*}{ Fatty acids } & \multicolumn{2}{|l|}{$\mathrm{CM}$} & \multicolumn{2}{|l|}{$\mathrm{RM}(30 \mathrm{~min})$} & \multicolumn{2}{|l|}{$\mathrm{RM}(60 \mathrm{~min})$} & \multicolumn{2}{|l|}{ RMS (30 min) } & \multicolumn{2}{|l|}{ RMS (60 min) } \\
\hline & $\begin{array}{l}\text { Mean } \pm \text { SD } \\
\left(n g \mu L^{-1}\right)\end{array}$ & $\mathrm{CV}(\%)$ & $\begin{array}{l}\text { Mean } \pm \text { SD } \\
\left(n g \mu L^{-1}\right)\end{array}$ & $\mathrm{CV}(\%)$ & $\begin{array}{l}\text { Mean } \pm \text { SD } \\
\left(n g \mu L^{-1}\right)\end{array}$ & $\mathrm{CV}(\%)$ & $\begin{array}{l}\text { Mean } \pm \text { SD } \\
\left(n g \mu L^{-1}\right)\end{array}$ & $\mathrm{CV}(\%)$ & $\begin{array}{l}\text { Mean } \pm \text { SD } \\
\left(\operatorname{ng} \mu L^{-1}\right)\end{array}$ & $\mathrm{CV}(\%)$ \\
\hline \multicolumn{11}{|l|}{ SFA } \\
\hline $14: 0$ & $2.17 \pm 0.07$ & 3.3 & $5.91 \pm 0.09$ & 1.5 & $11.31 \pm 0.18$ & 1.6 & $7.03 \pm 0.23$ & 3.3 & $7.67 \pm 0.43$ & 5.6 \\
\hline $15: 0$ & n.q & - & $0.68 \pm 0.01$ & 0.7 & $1.55 \pm 0.05$ & 3.2 & $1.55 \pm 0.08$ & 5.1 & $1.60 \pm 0.01$ & 0.4 \\
\hline $16: 0$ & $301.70 \pm 18.12$ & 6.0 & $523.40 \pm 0.40$ & 0.1 & $744.14 \pm 28.62$ & 3.8 & $690.22 \pm 17.19$ & 2.5 & $750.06 \pm 6.66$ & 0.9 \\
\hline $17: 0$ & n.q & - & $2.54 \pm 0.08$ & 3.1 & $6.64 \pm 0.29$ & 4.4 & $4.10 \pm 0.77$ & 1.7 & $6.20 \pm 0.19$ & 3.0 \\
\hline 18:0 & $260.07 \pm 7.26$ & 2.8 & $394.21 \pm 8.61$ & 2.2 & $515.78 \pm 14.52$ & 2.8 & $543.16 \pm 30.26$ & 5.6 & $553.71 \pm 2.17$ & 0.4 \\
\hline $20: 0$ & $9.18 \pm 0.04$ & 0.4 & $6.46 \pm 0.16$ & 2.4 & $11.12 \pm 0.54$ & 4.9 & $7.03 \pm 0.58$ & 8.3 & $11.04 \pm 0.04$ & 0.4 \\
\hline $22: 0$ & $4.29 \pm 1.03$ & 23.9 & $42.74 \pm 1.53$ & 3.6 & $77.57 \pm 4.38$ & 5.6 & $53.96 \pm 0.46$ & 0.8 & $76.17 \pm 1.29$ & 1.7 \\
\hline $23: 0$ & n.d. & - & n.d. & - & $2.61 \pm 0.16$ & 6.3 & n.d. & - & $1.72 \pm 0.01$ & 0.6 \\
\hline $24: 0$ & $2.23 \pm 0.00$ & 0.2 & $18.08 \pm 0.21$ & 1.1 & $93.28 \pm 4.55$ & 4.6 & $17.30 \pm 0.55$ & 3.0 & $87.83 \pm 1.75$ & 1.9 \\
\hline \multicolumn{11}{|l|}{ MUFA } \\
\hline $16: 1$ & n.d. & - & $7.43 \pm 0.24$ & 3.2 & $11.02 \pm 0.35$ & 3.2 & $10.41 \pm 0.23$ & 1.7 & $10.42 \pm 0.08$ & 0.8 \\
\hline $18: \ln 9 \mathrm{t}$ & n.d. & - & n.d. & - & n.d. & - & $13.35 \pm 0.71$ & 5.3 & $9.08 \pm 0.08$ & 0.9 \\
\hline $18: \ln 9 \mathrm{c}$ & $66.77 \pm 19.69$ & 29.5 & $242.88 \pm 5.30$ & 2.2 & $316.40 \pm 1.53$ & 0.5 & $317.07 \pm 0.32$ & 0.1 & $316.28 \pm 3.59$ & 1.1 \\
\hline $18: 1 \mathrm{n} 7$ & n.q & - & $15.66 \pm 0.31$ & 2.0 & $21.54 \pm 0.02$ & 0.1 & $21.79 \pm 0.42$ & 1.9 & $20.87 \pm 0.46$ & 2.2 \\
\hline $18: 1 \mathrm{n} 6$ & n.d. & - & $3.51 \pm 0.13$ & 3.6 & $9.49 \pm 0.51$ & 5.4 & $7.35 \pm 0.48$ & 6.5 & $5.42 \pm 0.59$ & 10.9 \\
\hline $20: 1$ & n.q & - & $0.79 \pm 0.04$ & 5.2 & $1.08 \pm 0.02$ & 2.1 & $1.27 \pm 0.05$ & 4.3 & $1.35 \pm 0.02$ & 1.4 \\
\hline $22: 1 n 9$ & n.d. & - & n.d. & - & n.d. & - & $4.35 \pm 0.18$ & 4.2 & $2.72 \pm 0.06$ & 2.3 \\
\hline $24: 1$ & n.q & - & $16.17 \pm 0.48$ & 3.0 & $102.41 \pm 3.50$ & 3.4 & $14.64 \pm 0.58$ & 4.0 & $86.82 \pm 1.84$ & 2.1 \\
\hline \multicolumn{11}{|l|}{ n-6 PUFA } \\
\hline $18: 2 \mathrm{n} 6 \mathrm{c}$ & $37.18 \pm 15.70$ & 42.2 & $186.11 \pm 6.83$ & 3.7 & $243.24 \pm 1.94$ & 0.8 & $225.30 \pm 3.76$ & 1.7 & $227.75 \pm 3.82$ & 1.7 \\
\hline $20: 2$ & n.d. & - & $4.77 \pm 0.04$ & 0.9 & $6.95 \pm 0.15$ & 2.1 & $6.82 \pm 0.06$ & 0.8 & $6.92 \pm 0.06$ & 0.8 \\
\hline $20: 4 n 6$ & $42.60 \pm 15.01$ & 35.2 & $316.18 \pm 11.27$ & 3.6 & $427.60 \pm 0.28$ & 0.1 & $382.96 \pm 4.11$ & 1.0 & $386.46 \pm 6.09$ & 1.6 \\
\hline $22: 4 n 6$ & $7.55 \pm 2.93$ & 38.8 & $76.35 \pm 2.83$ & 3.7 & $89.49 \pm 0.13$ & 0.1 & $93.95 \pm 0.80$ & 0.8 & $85.93 \pm 1.11$ & 1.3 \\
\hline $22: 5 n 6$ & n.d. & - & $13.23 \pm 0.68$ & 5.1 & $21.22 \pm 0.05$ & 0.3 & $18.07 \pm 0.09$ & 0.5 & $19.36 \pm 0.19$ & 1.0 \\
\hline $24: 2 \mathrm{n} 6$ & n.d. & - & n.q & - & $10.27 \pm 0.30$ & 3.0 & n.q & - & $9.24 \pm 0.15$ & 1.6 \\
\hline \multicolumn{11}{|l|}{ n-3 PUFA } \\
\hline $18: 3 n 3$ & n.q & - & $3.03 \pm 0.07$ & 2.2 & $3.78 \pm 0.07$ & 1.8 & $4.25 \pm 026$ & 6.0 & $4.22 \pm 0.11$ & 2.6 \\
\hline $20: 5 n 3$ & n.d. & - & $2.98 \pm 0.08$ & 2.4 & $6.17 \pm 0.03$ & 0.5 & $4.69 \pm 0.20$ & 4.1 & $4.64 \pm 0.23$ & 4.7 \\
\hline $22: 5 n 3$ & n.d. & - & $23.75 \pm 1.03$ & 4.3 & $29.51 \pm 0.05$ & 0.2 & $29.99 \pm 0.06$ & 0.2 & $29.15 \pm 0.42$ & 1.4 \\
\hline $22: 6 n 3$ & $23.02 \pm 7.92$ & 34.4 & $125.47 \pm 6.81$ & 5.4 & $166.70 \pm 1.24$ & 0.7 & $151.08 \pm 3.01$ & 2.0 & $152.85 \pm 1.59$ & 1.0 \\
\hline
\end{tabular}

The yields of fatty acid are shown as mean $(n=9) \pm$ standard deviation $(\mathrm{SD})$ and coefficient of variation $(\mathrm{CV} \%)$

n.q. below LOQ, n.d. below LOD. $C M$ classic method, $R M$ rapid method, $R M S$ rapid method with saponification, $S F A$ saturated fatty acids, MUFA monounsaturated fatty acids, $P U F A$ polyunsaturated fatty acids

In this work, FAs were analysed as FAME derivatives and the obtained results converted to FA as proposed by Sheppard (1982). The results of individual FA (ng $\mu \mathrm{L}^{-1}$ ) from analysed RBCs using the different evaluated methodologies are presented in Table 1 . The concentration of total saturated (SFA), monounsaturated (MUFA) and polyunsaturated (PUFA) FAs is highlighted in Fig. 1. Compared to all rapid methods tested, the conventional two-step method resulted in a lower number of identified FAMEs (with some FAs being detected but below the LOQ) (Table 1) and lower yields for most FA groups, with exception for SFA (Fig. 1). This is in good agreement with the results reported by
Böcking et al. [47] and is possibly explained by the clotting of RBCs membrane proteins caused by chloroform, which can hamper FA extraction in this particular matrix. Furthermore, a lower amount of the IS was recovered using this method (data not shown), pointing to an inevitable loss of compounds due to sample transfers among vials in the separate steps of extraction and methylation. Regarding the one-step methods (designated as RM and RMS), the four tested protocols led to comparable qualitative FA patterns but different absolute concentrations of individual FA and sum of compounds (Table 1). In general, the use of a longer methylation period $(60 \mathrm{~min})$, either with or without 
Fig. 1 Comparison of FA groups (ng $\mu \mathrm{L}^{-1}$ ) obtained from RBCs using different transesterification methods ( $C M$ conventional two-step method, $R M$ rapid method, $R M S$ rapid method with saponification). SFA saturated fatty acids, MUFA monounsaturated fatty acids, PUFA polyunsaturated fatty acids; error bars the standard deviation, all results are shown as mean $\pm \mathrm{SD}(n=9)$
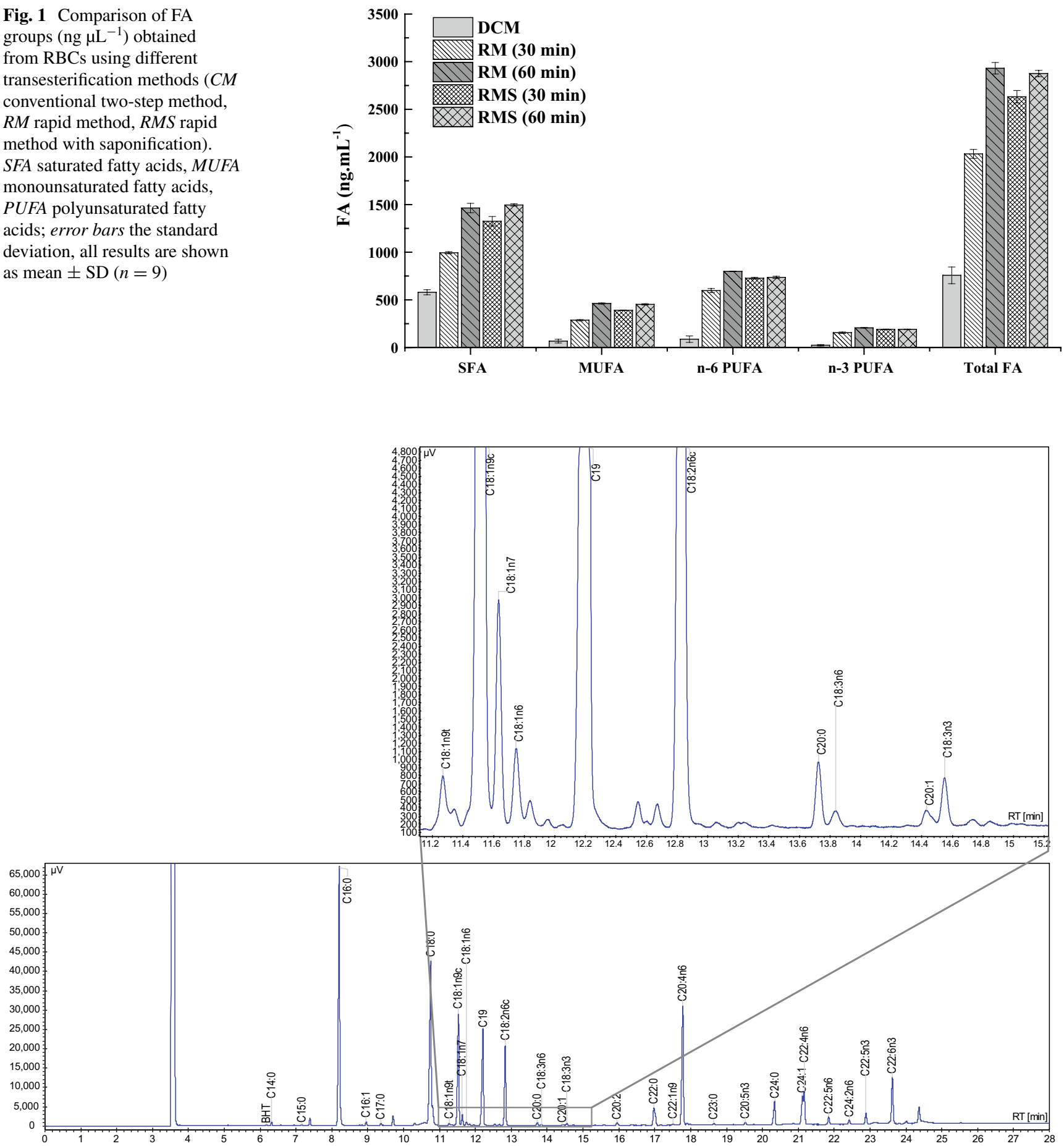

Fig. 2 GC-FID chromatogram obtained from the analysis of an RBC sample with the selected method (RMS-60 min) evidencing the separation profile of the identified unsaturated C18 isomers and the internal standard (C19:0)

$\mathrm{KOH}$ saponification, allowed obtaining higher amounts (ng $\mu \mathrm{L}^{-1}$ ) for most FAMEs (Fig. 1), with particular emphasis for lignoceric acid (C24:0) and very long-chain FAs docosanoic (C22:0), tricosanoic acid (23:0) and nervonic acid (C24:1) (Table 1). On the other hand, the use of saponification allowed the detection of some important trans and cis FAs that were not detected with other methods (Table 1), namely the trans isomer of oleic acid, elaidic acid (C18:1n9t), which is the major trans FA frequently associated with increased risk of cardiovascular diseases [1, 48], and the cis erucic acid (C22:1n9), which has been related with myocardial lesions [49]. Considering that the one-step 
RMS method with a longer methylation period $(60 \mathrm{~min})$ allowed to simultaneously achieve a high extraction yield for most compounds, as well as to identify a higher number of FAs, with particular emphasis for the detection of trans FAs, it was selected as being the most suitable methodology for the intended purposes (being used in future biomedical/ epidemiological studies). Therefore, it was further submitted to in-house validation, where the most common validation parameters were evaluated. A typical chromatogram obtained for a RBC sample analysed using the selected method (rapid method with saponification and 60 min methylation period, RMS-60 min) is shown in Fig. 2.

\section{Linearity and Sensitivity of the GC-FID Analysis}

Table 2 presents the results obtained for the linearity, LOD and LOQ. As referred, for each compound an eight-level calibration curve was constructed using the peak area versus concentration of the standard $\left(\mu \mathrm{g} \mu \mathrm{L}^{-1}\right)$. An adequate linearity over the concentration range studied was obtained for all investigated FAMEs, with correlation coefficient values $\left(r^{2}\right)$ higher than 0.999 , except for C20:0 with an $r^{2}$ value of 0.998 (Table 2). To calculate the linear FID response for each FAME, slope and intercept of the individual FA were used. The slopes values for the majority of the FAMEs were similar, nevertheless there were some exceptions demonstrating the importance of quantifying each compound using appropriate calibration curves obtained with the corresponding standard. To determine the sensitivity of the FAMEs analysis, LOD and LOQ were calculated as three times and ten times standard deviation of signalto-noise $(S / N)$ ratio. As can be observed in Table 2, LOD ranged between 0.073 and $0.205 \mathrm{ng} \mu \mathrm{L}^{-1}$ and LOQ ranged between 0.242 and $0.631 \mathrm{ng}_{\mu} \mathrm{L}^{-1}$.
Table 2 Linearity and sensitivity of the fatty acids methyl esters (FAME) detection by GC-FID analysis

\begin{tabular}{|c|c|c|c|c|c|c|c|}
\hline Fatty acids & $\mathrm{Rt}(\min )$ & Range (ng $\mu \mathrm{l}^{-1}$ ) & Slope $^{a}$ & Intercept $^{\mathrm{a}}$ & $r^{2}$ & $\operatorname{LOD}\left(\operatorname{ng} \mu 1^{-1}\right)$ & LOQ $\left(n g \mu l^{-1}\right)$ \\
\hline $14: 0$ & 6.37 & $400.0-0.82$ & 7656.9 & 6.9509 & 0.9995 & 0.199 & 0.588 \\
\hline $15: 0$ & 7.21 & $200.0-0.41$ & 7627.2 & 5.1976 & 0.9997 & 0.200 & 0.590 \\
\hline $16: 0$ & 8.24 & $602.0-1.24$ & 7894.3 & 9.2202 & 0.9995 & 0.193 & 0.570 \\
\hline $16: 1$ & 9.00 & $199.0-0.41$ & 7781.5 & 4.3558 & 0.9995 & 0.196 & 0.578 \\
\hline $17: 0$ & 9.42 & $200.0-0.41$ & 7806.3 & 4.6604 & 0.9995 & 0.195 & 0.577 \\
\hline $18: 0$ & 10.78 & $399.0-0.82$ & 7984.7 & 8.8242 & 0.9996 & 0.191 & 0.564 \\
\hline $18: \ln 9 \mathrm{t}$ & 11.32 & $200.0-0.41$ & 7597.8 & 5.0329 & 0.9996 & 0.200 & 0.592 \\
\hline $18: \ln 9 \mathrm{c}$ & 11.57 & $399.0-0.82$ & 8053.0 & 7.5348 & 0.9995 & 0.189 & 0.559 \\
\hline $18: \ln 7^{b}$ & 11.67 & $600.0-2.34$ & 8440.7 & 17.552 & 0.9999 & 0.073 & 0.242 \\
\hline $18: 1 \mathrm{n} 6^{\mathrm{b}}$ & 11.79 & $600.0-2.34$ & 8440.7 & 17.552 & 0.9999 & 0.073 & 0.242 \\
\hline $18: 2 \mathrm{n} 6 \mathrm{c}$ & 12.87 & $200.0-0.41$ & 7851.2 & 5.0025 & 0.9995 & 0.194 & 0.573 \\
\hline $20: 0$ & 13.82 & $402.0-0.83$ & 8632.8 & 15.848 & 0.9988 & 0.176 & 0.521 \\
\hline $20: 1$ & 14.48 & $199.0-0.41$ & 7825.9 & 4.2181 & 0.9996 & 0.195 & 0.575 \\
\hline $18: 3 n 3$ & 14.61 & $200.0-0.41$ & 8068.9 & 5.7257 & 0.9997 & 0.189 & 0.558 \\
\hline $20: 2$ & 16.01 & $200.0-0.41$ & 7906.8 & 4.704 & 0.9997 & 0.193 & 0.569 \\
\hline $22: 0$ & 17.02 & $601.0-1.24$ & 7682.7 & 15.337 & 0.9997 & 0.198 & 0.586 \\
\hline $22: 1 \mathrm{n} 9$ & 17.67 & $201.0-0.41$ & 7438.7 & 5.0574 & 0.9997 & 0.205 & 0.605 \\
\hline $20: 4 n 6$ & 17.81 & $403.0-0.83$ & 7680.9 & 7.601 & 0.9997 & 0.198 & 0.586 \\
\hline $23: 0$ & 18.75 & $200.0-0.41$ & 7994.7 & 8.2742 & 0.9997 & 0.190 & 0.563 \\
\hline $20: 5 n 3$ & 19.57 & 399.0-0.76 & 8131.5 & 11.725 & 0.9998 & 0.187 & 0.554 \\
\hline $24: 0$ & 20.43 & $199.0-0.43$ & 7138.5 & 5.4313 & 0.9997 & 0.213 & 0.631 \\
\hline $24: 1$ & 21.17 & $200.0-0.41$ & 8021.6 & 7.7355 & 0.9997 & 0.190 & 0.561 \\
\hline $22: 4 n 6^{b}$ & 21.20 & $600.0-2.34$ & 8440.7 & 17.552 & 0.9999 & 0.073 & 0.242 \\
\hline $22: 5 n 6^{b}$ & 21.89 & $600.0-2.34$ & 8440.7 & 17.552 & 0.9999 & 0.073 & 0.242 \\
\hline $24: 2 n 6^{b}$ & 22.46 & $600.0-2.34$ & 8440.7 & 17.552 & 0.9999 & 0.073 & 0.242 \\
\hline $22: 5 n 3^{b}$ & 22.93 & $600.0-2.34$ & 8440.7 & 17.552 & 0.9999 & 0.073 & 0.242 \\
\hline $22: 6 n 3$ & 23.66 & $201.0-0.41$ & 7651.3 & 6.6866 & 0.9996 & 0.199 & 0.588 \\
\hline
\end{tabular}

$R t$ retention time, $r^{2}$ coefficient of correlation, $L O D$ limit of detection, $L O Q$ limit of quantification

${ }^{a}$ Based on eight-point calibration curve for each individual FA

${ }^{b}$ FAs identified by comparison with published data [32] and quantified using the C19:0 FAME calibration curve 


\section{Precision and Recovery}

An important aspect when implementing a new methodology in clinical studies is that it should be thoroughly

Table 3 Validation parameters for the selected methodology (RMS$60 \mathrm{~min}$ ) to analyse fatty acids in human RBCs

\begin{tabular}{|c|c|c|c|c|}
\hline \multirow[t]{2}{*}{ Fatty acids } & \multirow{2}{*}{$\begin{array}{l}\text { Repeatability } \\
\mathrm{CV}(\%)^{\mathrm{a}}\end{array}$} & \multirow{2}{*}{$\begin{array}{l}\text { Intermediate } \\
\text { precision } \\
\mathrm{CV}(\%)^{\mathrm{b}}\end{array}$} & \multicolumn{2}{|l|}{ Accuracy } \\
\hline & & & Recovery (\%) & $\mathrm{CV}(\%)$ \\
\hline $14: 0$ & 2.2 & 4.5 & $86.1 \pm 9.2$ & 10.7 \\
\hline $15: 0$ & 3.0 & 5.3 & $90.8 \pm 9.4$ & 10.3 \\
\hline $16: 0$ & 2.1 & 3.1 & $96.6 \pm 7.8$ & 8.2 \\
\hline $17: 0$ & 1.6 & 2.6 & $99.3 \pm 10.9$ & 11.0 \\
\hline $18: 0$ & 2.2 & 3.8 & $98.1 \pm 7.3$ & 7.5 \\
\hline $20: 0$ & 2.2 & 3.9 & $90.2 \pm 8.1$ & 9.0 \\
\hline $22: 0$ & 1.9 & 3.5 & $72.4 \pm 10.6$ & 14.6 \\
\hline $23: 0$ & 3.4 & 4.6 & $102.4 \pm 11.0$ & 10.8 \\
\hline $24: 0$ & 2.2 & 3.5 & $97.2 \pm 9.6$ & 9.9 \\
\hline SFA & 2.3 & 3.9 & - & - \\
\hline $16: 1$ & 2.6 & 2.3 & $91.2 \pm 9.7$ & 10.7 \\
\hline $18: \ln 9 \mathrm{t}$ & 2.3 & 2.2 & $95.9 \pm 8.1$ & 8.4 \\
\hline $18: \ln 9 \mathrm{c}$ & 2.0 & 3.1 & $101.5 \pm 10.6$ & 10.5 \\
\hline $18: \ln 7^{c}$ & 2.1 & 2.6 & n.a. & n.a. \\
\hline $18: 1 \mathrm{n} 6^{\mathrm{c}}$ & 1.0 & 3.2 & n.a. & n.a. \\
\hline $20: 1$ & 2.6 & 5.3 & $87.8 \pm 9.5$ & 10.8 \\
\hline $22: \ln 9$ & 1.4 & 4.6 & $87.6 \pm 7.2$ & 8.2 \\
\hline $24: 1$ & 2.9 & 5.7 & $106.5 \pm 21.3$ & 20.0 \\
\hline MUFA & 2.1 & 3.6 & - & - \\
\hline $18: 2 \mathrm{n} 6 \mathrm{c}$ & 2.1 & 3.2 & $122.8 \pm 6.0$ & 4.9 \\
\hline $20: 2$ & 2.4 & 3.5 & $97.9 \pm 12.4$ & 12.6 \\
\hline $20: 4 n 6$ & 2.3 & 3.4 & $101.1 \pm 25.8$ & 25.6 \\
\hline $22: 4 n 6^{c}$ & 2.5 & 5.7 & n.a. & n.a. \\
\hline $22: 5 n 6^{c}$ & 4.6 & 6.5 & n.a. & n.a. \\
\hline $24: 2 n 6^{c}$ & 1.8 & 4.5 & n.a. & n.a. \\
\hline n-6 PUFA & 2.6 & 4.5 & - & - \\
\hline $18: 3 n 3$ & 4.9 & 5.8 & $97.4 \pm 10.2$ & 10.5 \\
\hline $20: 5 n 3$ & 2.5 & 3.3 & $93.6 \pm 14.2$ & 15.2 \\
\hline $22: 5 n 3^{c}$ & 1.7 & 3.0 & n.a. & n.a. \\
\hline $22: 6 n 3$ & 1.6 & 2.8 & $128.4 \pm 3.7$ & 2.9 \\
\hline n-3 PUFA & 2.7 & 3.7 & - & - \\
\hline
\end{tabular}

Bold highlights the mean CV (\%) of the total SFA, MUFA, n-3 PUFA and n-6 PUFA

SFA saturated fatty acids, MUFA monounsaturated fatty acids, PUFA polyunsaturated fatty acids, $C V(\%)$ coefficient of variation, n.a. not applicable (without recovery data as they are not present in standard mix)

a sixfold determination of the sample at 1 day $(n=12)$

b determination of the sample in duplicates during 5 days in a week $(n=10)$

${ }^{c}$ Identified FAs by comparison with published data [32] evaluated before being used. Nevertheless, several clinical and nutritional studies reported so far do not give any information regarding the use of methodologies validated for the specific analysis of RBCs, which is a matrix very different from tissues, plasma and whole blood.

To assess the precision of the selected method (RMS), repeatability and intermediate precision were determined as the coefficient of variation (CV \%) obtained for intraday and interday precision, respectively. The obtained experimental CV \% was in the range of $1.0-4.9 \%$ for repeatability and $2.2-6.5 \%$ for intermediate precision (Table 3 ). The comparison of these values with the theoretical repeatability and intermediate precision CV \% (obtained from the Horwitz equation and the Horrat value for an analyte ratio of $10^{-6}\left(\mathrm{ng} \mu \mathrm{L}^{-1}\right)$ as reported in the guidelines for validation of chromatographic methods [37]) showed a high precision of the method, as the experimental values were always lower than the theoretical coefficient of variation recommended for this order of analyte level. However, it should be referred that, in general, there was an increase in the coefficient of variation calculated for interday precision when compared to intraday precision values obtained for the same compounds. This was particularly noticed for the unsaturated acids, possibly because they are more susceptible to oxidation. Therefore, besides adding an antioxidant, the samples should be handled under an atmosphere of inert gas and stored at $-20{ }^{\circ} \mathrm{C}$ whenever needed. Finally, the accuracy of the selected method was assessed by calculating the mean recovery of the individual FAMEs (Table 3) from samples of RBCs spiked with 15 and 25 $\mu \mathrm{L}$ of the stock solution of 37 FAMEs Certified Reference Material $\left(10 \mathrm{mg} \mathrm{mL}^{-1}\right)$, and subjected to FAMEs extraction with the selected method (RMS with 60 min methylation). In general, recoveries of each FAME exceeded $80 \%$, which is in good agreement with the recommended theoretical recovery values (80-110\%) [37]. Although not considered due to their absence in the analysis of RBCs, it can be referred that lower recovery values (ranging from 23.7 to $77.4 \%$ ) were obtained for short chain FAs, namely $\mathrm{C} 10: 0, \mathrm{C} 11: 0, \mathrm{C} 12: 0$ and $\mathrm{C} 13: 0$ possibly due to incomplete extraction of the compounds to $n$-heptane. Low recoveries for short chain FAs were already reported by Firl et al. [19] when developing and validating a methodology for FA analysis in human plasma. However, higher recovery was attained in the present work for myristic acid (C14:0) compared to the values achieved for plasma reported by Firl et al. [19].

\section{Application of the Method}

As an application example, the proposed validated method was applied for the analysis of a RBC sample obtained from a patient with type 2 Diabetes mellitus (T2DM) and 
Fig. 3 Comparison FA (\%) profile between a healthy volunteer and a type 2 Diabetes mellitus (T2DM) patient, obtained using the validated transesterification method RMS-60 min; error bars the standard deviation $(n=3)$

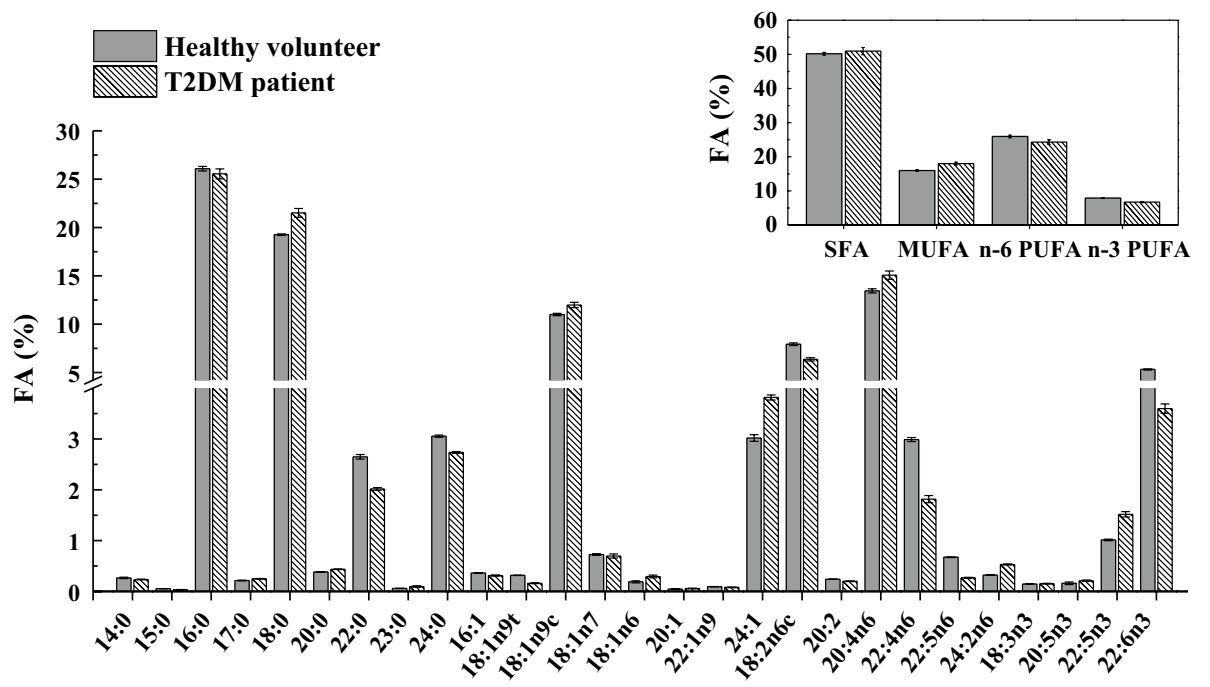

results compared with the values obtained for a healthy volunteer (without T2DM) (Fig. 3). The graphic presented in Fig. 3 shows a higher MUFA content in the T2DM RBC sample which has already been described in this type of patients being attributed to a stimulation of $\Delta^{9}$ desaturase enzymes, which converts SFA in MUFA, caused by increased glucose uptake in patients with T2DM [6]. Also, in good agreement with the literature [6] results showed that the patient with T2DM presented higher levels of some long-chain SFA such as arachidic acid (C20:0) and lower levels of PUFA, in particular of the omega-3 docosahexaenoic acid (DHA, C22:6n3), although showing higher contents of the omega-6 arachidonic acid (AA, C20:4n6).

\section{Conclusions}

In this work, an optimized one-step sample preparation methodology for FA analysis in human RBCs samples is proposed. Based on the presented results, the validated methodology for the quantification of FAs in human RBCs showed to be fast, sensitive, precise and accurate, thus demonstrating its suitability as a useful tool that can be used in clinical and epidemiological surveys including a high number of samples.

Acknowledgments This work received financial support from the European Union (FEDER funds through COMPETE) and National Funds (FCT, Fundação para a Ciência e Tecnologia) through project PTDC/SAU-ENB/116929/2010 and EXPL/EMS-SIS/2215/2013. ROR acknowledges PhD scholarship SFRH/BD/97658/2013 attributed by FCT (Fundação para a Ciência e Tecnologia).

\section{Compliance with Ethical Standards}

Conflict of interest The authors declare that they have no conflict of interest.

\section{References}

1. Rustan AC, Drevon CA (2001) Fatty acids: structures and properties. eLS. Wiley

2. Berry EM, Eisenberg S, Haratz D, Friedlander Y, Norman Y, Kaufmann NA, Stein Y (1991) Effects of diets rich in monounsaturated fatty acids on plasma lipoproteins-the Jerusalem Nutrition Study: high MUFAs vs high PUFAs. Am J Clin Nutr 53(4):899-907

3. Djousse L, Matthan NR, Lichtenstein AH, Gaziano JM (2012) Red blood cell membrane concentration of cis-palmitoleic and cis-vaccenic acids and risk of coronary heart disease. Am J Cardiol 110(4):539-544

4. Novgorodtseva T, Kantur T, Karaman Y, Antonyuk M, Zhukova N (2011) Modification of fatty acids composition in erythrocytes lipids in arterial hypertension associated with dyslipidemia. Lipids Health Dis 10(1):18

5. Shearer GC, Pottala JV, Spertus JA, Harris WS (2009) Red Blood cell fatty acid patterns and acute coronary syndrome. PLoS ONE 4(5): e5444

6. Sertoglu E, Kurt I, Tapan S, Uyanik M, Serdar MA, Kayadibi H, El-Fawaeir S (2014) Comparison of plasma and erythrocyte membrane fatty acid compositions in patients with end-stage renal disease and type 2 diabetes mellitus. Chem Phys Lipids 178:11-17

7. Yu DX, Sun Q, Ye XW, Pan A, Zong G, Zhou YH, Li HX, Hu FB, Lin X (2012) Erythrocyte trans-fatty acids, type 2 diabetes and cardiovascular risk factors in middle-aged and older Chinese individuals. Diabetologia 55(11):2954-2962

8. Yue KT, Davis JW, Phillips PE, Graham BA (1981) Effect of glucose on plasma concentrations of individual non-esterified fatty acids of non-diabetic and insulin-independent diabetic men. Postgrad Med J 57(672):622-626

9. Harris RB, Foote JA, Hakim IA, Bronson DL, Alberts DS (2005) Fatty acid composition of red blood cell membranes and risk of squamous cell carcinoma of the skin. Cancer Epidemiol Biomarkers Prev 14(4):906-912

10. Conquer J, Tierney M, Zecevic J, Bettger W, Fisher R (2000) Fatty acid analysis of blood plasma of patients with alzheimer's disease, other types of dementia, and cognitive impairment. Lipids 35(12):1305-1312

11. Freeman MP (2006) Omega-3 fatty acids and perinatal depression: a review of the literature and recommendations for 
future research. Prostaglandins LeukotEssent Fatty Acids 75(4-5):291-297

12. Hodson L, Skeaff CM, Fielding BA (2008) Fatty acid composition of adipose tissue and blood in humans and its use as a biomarker of dietary intake. Prog Lipid Res 47(5):348-380

13. Acar N, Berdeaux O, Grégoire S, Cabaret S, Martine L, Gain P, Thuret G, Creuzot-Garcher CP, Bron AM, Bretillon L (2012) Lipid Composition of the human eye: are red blood cells a good mirror of retinal and optic nerve fatty acids? PLoS ONE 7(4):e35102

14. Catalan U, Rodriguez MA, Ras MR, Macia A, Mallol R, Vinaixa M, Fernandez-Castillejo S, Valls RM, Pedret A, Griffin JL, Salek R, Correig X, Motilva MJ, Sola R (2013) Biomarkers of food intake and metabolite differences between plasma and red blood cell matrices; a human metabolomic profile approach. Mol BioSyst 9(6): 1411-1422

15. Shemin D, Rittenberg D (1946) The life span of the human red blood cell. J Biol Chem 166(2):627-636

16. Clayton E, Gulliver C, Piltz J, Taylor R, Blake R, Meyer R (2012) Improved extraction of saturated fatty acids but not omega-3 fatty acids from sheep red blood cells using a one-step extraction procedure. Lipids 47(7):719-727

17. Cao J, Schwichtenberg KA, Hanson NQ, Tsai MY (2006) Incorporation and clearance of omega- 3 fatty acids in erythrocyte membranes and plasma phospholipids. Clin Chem 52(12):2265-2272

18. Courville AB, Keplinger MR, Judge MP, Lammi-Keefe CJ (2009) Plasma or red blood cell phospholipids can be used to assess docosahexaenoic acid status in women during pregnancy. Nutr Res 29(3):151-155

19. Firl N, Kienberger H, Hauser T, Rychlik M (2013) Determination of the fatty acid profile of neutral lipids, free fatty acids and phospholipids in human plasma. Clin Chem Lab Med 51(4):799-810

20. Folch J, Lees M, Sloane Stanley GH (1957) A simple method for the isolation and purification of total lipides from animal tissues. J Biol Chem 226(1):497-509

21. Rizzo A, Montorfano G, Negroni M, Adorni L, Berselli P, Corsetto P, Wahle K, Berra B (2010) A rapid method for determining arachidonic:eicosapentaenoic acid ratios in whole blood lipids: correlation with erythrocyte membrane ratios and validation in a large Italian population of various ages and pathologies. Lipids Health Dis 9(1):7

22. Bailey-Hall E, Nelson EB, Ryan AS (2008) Validation of a rapid measure of blood PUFA levels in humans. Lipids 43(2):181-186

23. Bell JG, Mackinlay EE, Dick JR, Younger I, Lands B, Gilhooly $\mathrm{T}$ (2011) Using a fingertip whole blood sample for rapid fatty acid measurement: method validation and correlation with erythrocyte polar lipid compositions in UK subjects. Br J Nutr 106(9):1408-1415

24. Bligh EG, Dyer WJ (1959) A rapid method of total lipid extraction and purification. Can J Biochem 37(8):911-917

25. Araujo P, Nguyen TT, Froyland L, Wang J, Kang JX (2008) Evaluation of a rapid method for the quantitative analysis of fatty acids in various matrices. J Chromatogr A 1212(1-2):106-113

26. Kang J, Wang J (2005) A simplified method for analysis of polyunsaturated fatty acids. BMC Biochem 6(1):5

27. Bondia-Pons I, Castellote AI, López-Sabater MC (2004) Comparison of conventional and fast gas chromatography in human plasma fatty acid determination. J Chromatogr B 809(2):339-344

28. Dole VP, Meinertz H (1960) Microdetermination of long-chain fatty acids in plasma and tissues. J Biol Chem 235(9):2595-2599

29. Kangani CO, Kelley DE, Delany JP (2008) New method for GC/ FID and GC-C-IRMS analysis of plasma free fatty acid concentration and isotopic enrichment. J Chromatogr B Analyt Technol Biomed Life Sci 873(1):95-101
30. Kopf T, Schmitz G (2013) Analysis of non-esterified fatty acids in human samples by solid-phase-extraction and gas chromatography/mass spectrometry. J Chromatogr B Analyt Technol Biomed Life Sci 938:22-26

31. Lepage G, Roy CC (1986) Direct transesterification of all classes of lipids in a one-step reaction. J Lipid Res 27(1):114-120

32. Bicalho B, David F, Rumplel K, Kindt E, Sandra P (2008) Creating a fatty acid methyl ester database for lipid profiling in a single drop of human blood using high resolution capillary gas chromatography and mass spectrometry. J Chromatogr A 1211(1-2):120-128

33. Burrows T, Berthon B, Garg ML, Collins CE (2012) A comparative validation of a child food frequency questionnaire using red blood cell membrane fatty acids. Eur J Clin Nutr 66(7):825-829

34. Magnusardottir AR, Steingrimsdottir L, Thorgeirsdottir $\mathrm{H}$, Gunnlaugsson G, Skuladottir GV (2009) Docosahexaenoic acid in red blood cells of women of reproductive age is positively associated with oral contraceptive use and physical activity. Prostaglandins Leukot Essent Fatty Acids 80(1):27-32

35. Meneses F, Ney JG, Torres AG, Trugo NM (2009) Erythrocyte membrane and plasma non-esterified n-3 and n-6 polyunsaturated fatty acids of pregnant and non-pregnant Brazilian adolescents. Prostaglandins Leukot Essent Fatty Acids 80(2-3):137-142

36. Sheppard AJ, Food US, Administration D (1992) Lipid manual: methodology suitable for fatty acid-cholesterol analysis. Wm. C. Brown Publishers, Iowa

37. Taverniers I, De Loose M, Van Bockstaele E (2004) Trends in quality in the analytical laboratory. II. Analytical method validation and quality assurance. TrAC, Trends. Anal Chem 23(8):535-552

38. International Conference on Harmonisation (October 1994/ November 1996) ICH harmonised tripartite guideline validation of analytical procedure: text and methodology Q2(R1), vol Q2(R1)

39. Amaral J, Casal S, Citová I, Santos A, Seabra R, Oliveira BP (2006) Characterization of several hazelnut (Corylus avellana L.) cultivars based in chemical, fatty acid and sterol composition. Eur Food Res Technol 222(3-4):274-280

40. ISO (2011) 12966-2:2011 Animal and vegetable fats and oilsgas chromatography of fatty acid methyl esters-part 2: preparation of methyl esters of fatty acids

41. Phillips KM, Ruggio DM, Howe JC, Leheska JM, Smith SB, Engle T, Rasor AS, Conley NA (2010) Preparation and characterization of control materials for the analysis of conjugated linoleic acid and trans-vaccenic acid in beef. Food Res Int 43(9):2253-2261

42. Magnusardottir AR, Skuladottir GV (2006) Effects of storage time and added antioxidant on fatty acid composition of red blood cells at -20 degrees C. Lipids 41(4):401-404

43. Schreiner M (2006) Principles for the Analysis of Omega-3 Fatty Acids. In: Teale MC (ed) Omega 3 fatty acid research. Nova Science Publishers, New York, pp 1-25

44. Morrison WR, Smith LM (1964) Preparation of fatty acid methyl esters and dimethylacetals from lipids with boron fluoride-methanol. J Lipid Res 5(4):600-608

45. IUPAC (1987) Standard methods for analysis of oils, fats and derivatives. IUPAC Method 2.301, Seventh edn. Blackwell Scientific Publications, Oxford

46. AOAC (1997) Fatty acids in oils and fats; preparation of methyl ester boron trifluoride method. AOAC Official Method 969.33. AOAC International

47. Bocking C, Nockher WA, Schreiner M, Renz H, Pfefferle PI (2010) Development and validation of a combined method for the biomonitoring of omega-3/-6 fatty acids and conjugated 
linoleic acids in different matrices from human and nutritional sources. Clin Chem Lab Med 48(12):1757-1763

48. Bhardwaj S, Passi SJ, Misra A (2011) Overview of trans fatty acids: biochemistry and health effects. Diabetes Metab Syndr 5(3):161-164
49. Kvannes J, Eikhom TS, Flatmark T (1995) On the mechanism of stimulation of peroxisomal $\beta$-oxidation in rat heart by partially hydrogenated fish oil. BBA-Lipid Lipid Met 1255(1):39-49 